\title{
Sphenoid sinus mucocele
}

\author{
Mohammed Bahgat, Yassin Bahgat, Ahmed Bahgat \\ Department of ENT and head \& neck surgery, Alexandria University Hospitals, ENT and Head \& Neck Surgery, Alexandria, Egypt
}

Correspondence to Mohammed Bahgat, mybahgat18@hotmail.com

\section{Summary}

The authors present their experience of managing an interesting case of a 65-year-old woman who presented to their clinic with 1-month history of persistent deep-seated headache. The patient sought medical advice in neurology and ophthalmology clinics before being referred to the ear, nose and throat clinic. CT imaging revealed isolated opacification and expansion of both sphenoid sinuses with bony continuity along the periphery of the sinuses features consistent with mucocele. MRI was needed to fully evaluate the extension of the lesion. The lesion was diagnosed as bilateral sphenoid sinuses mucoceles. Transnasal endoscopic drainage of the sphenoid mucoceles leads to gradual improvement of the symptoms. We discuss the clinical presentation, diagnosis and treatment of this case as well as a review of the literature.

\section{BACKGROUND}

Paranasal sinus mucocele is defined as the accumulation and retention of mucoid secretion within the sinus, leading to thinning, distension and erosion of one or several of its bony walls. Mucocele of the frontal sinus is most common, followed by an anterior ethmoidal sinus. Sphenoid sinus mucocele is the most rarely afflicted sinus and comprise $1-2 \%$ of all paranasal sinuses mucoceles, ${ }^{1}$ but when it is afflicted many vital complications may occur since several important structures including the dura, pituitary gland, optic nerve, cavernous sinus, internal carotid artery and cranial nerves (oculomotor, trochlear, trigeminal and abducent nerves) are adjacent to it. ${ }^{12}$

\section{CASE PRESENTATION}

A 65-year-old non-diabetic, non-hypertensive female patient, presented with a 1-month history of persistent deep-seated headache. The patient sought medical advice in neurology and ophthalmology clinics. Her visual acuity was normal with no diplopia, blepharoptosis, ophthalmoplegia, proptosis nor facial numbness. Clinical examination revealed pulse $85 / \mathrm{min}$.

Blood pressure 130/90 mm $\mathrm{Hg}$ and fundus examination was normal bilaterally. Field of vision by confrontation method did not reveal any field defects. There was no evidence of neck stiffness. Fasting blood sugar was $104 \mathrm{mg} / \mathrm{dl}$. She was consulted to the department of otolaryngology because CT imaging revealed isolated opacification and expansion of both sphenoid sinuses with bony continuity along the periphery of the sinus, features consistent with mucocele.

\section{INVESTIGATION}

CT imaging of the nose and paranasal sinuses revealed isolated opacification and expansion of both sphenoid sinuses with bony continuity along the periphery of the sinus consistent with bilateral sphenoid sinuses mucoceles (figure 1).

MRI was needed to fully evaluate the extension of the lesion. The sphenoid sinuses are expanded, showing thinning of their outlines and measuring $3.5 \times 2.5 \mathrm{~cm}$. Features of bilateral sphenoid sinuses mucoceles.

Normal size and shape of pituitary gland, normal opticchiasma and nerve complex, homogenous enhancement of the cavernous sinus were all detected. The brain reflects normal both cerebral and cerebellar hemispheres (figure 2).

\section{DIFFERENTIAL DIAGNOSIS}

Sphenoid sinus mucocele has varied presentations. Headache is the most common symptom of sphenoid sinus mucocele and it should be differentiated from other causes of headache which may be either due to ophthalmology causes (like acute angle closure glaucoma) or neurology causes (like causes of increased intracranial pressure). ${ }^{1}$

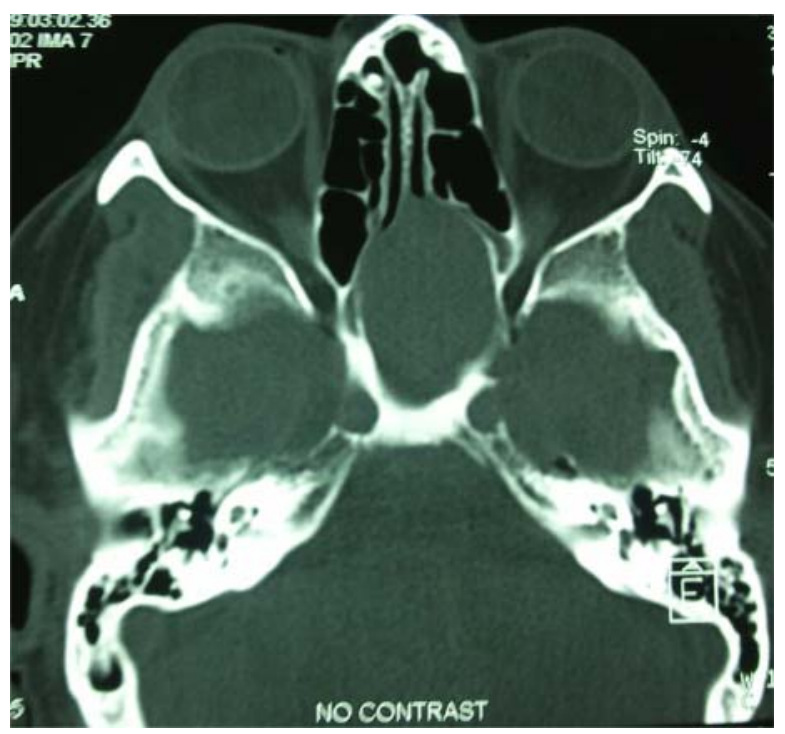

Figure 1 CT of the nose and paranasal sinuses (axial view) showing isolated opacification and expansion of both sphenoid sinuses with bony continuity along the periphery of the sinus consistent with bilateral sphenoid sinuses mucocele. 

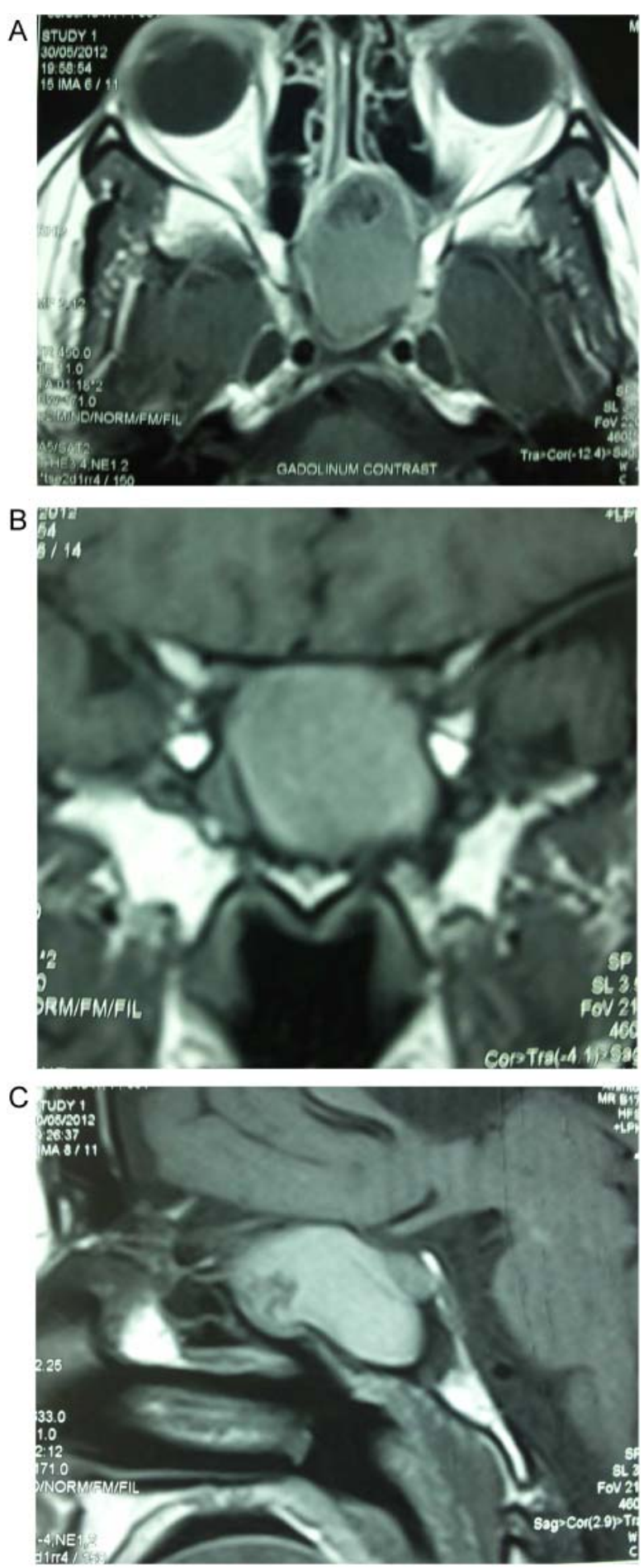

Figure $2(A-C) M R I$ of the nose and paranasal sinuses $(A$, axial view; $B$, coronal view and $C$, sagittal view) showing the sphenoid sinus expanding, showing thinning of its outlines and measuring $3.5 \times 2.5 \mathrm{~cm}$. Features of sphenoid sinus mucocele.

Expanding sphenoid sinus mucocele may compress the optic nerve or the cavernous sinus which carries the III, IV and VI nerves. So that sphenoid sinus mucocele should be kept in mind in cases of visual disturbances or III, IV and VI nerves palsy. ${ }^{2} 3$

Sphenoid sinus mucocele may present with painful ophthalmoplegia. Differential diagnosis of lesions producing painful opthalmoplegia includes pituitary apoplexy, ruptured intracranial berry aneurysm involving posterior communicating artery or the cavernous segment of the internal carotid artery, caroticocavernous fistula, nasopharyngeal carcinoma, metastatic carcinoma, herpes zoster opthalmicus, Tolosa-Hunt syndrome and opthalmoplegic migraine. ${ }^{3}$

\section{TREATMENT}

The patient underwent endoscopic drainage of both sphenoid sinuses under general anesthaesia. Intraoperatively, we made a new opening in the sphenoid sinus using upwardbiting and straight-biting forceps under endoscopic visualisation, and yellowish pus consistent with mucocele was seen filling the sinus. Sufficient removal of the anterior and inferior walls of the sphenoid sinuses was made to allow adequate drainage into sphenoehtmoidal recess and to avoid recurrence. The postoperative period was uneventful and the patient's symptoms gradually diminished. She has been followed in our outpatient clinic at regular intervals. On follow-up nasal endoscopy there is a healthy mucous membrane lined cavity widely open with no signs of recurrence nor other complications have been found and the patient remains asymptomatic.

\section{OUTCOME AND FOLLOW-UP}

After drainage surgery, the patient's symptoms gradually diminished. The patient continued to be followed at the outpatient department by clinical examination and nasal endoscopy.

\section{DISCUSSION}

Paranasal snius mucocele is defined as the accumulation and retention of mucoid secretion within the sinus, leading to thinning, distension and erosion of one or several of its bony walls.

Mucocele commonly affects the frontal and ethmoid sinuses, being less common in the maxillary sinuses, but rarely located in the sphenoid sinuses. Sphenoid sinus mucocele comprises $1-2 \%$ of all paranasal sinuses mucoceles. ${ }^{1}$ The first case of sphenoid mucocele was described by Berg in $1889 .^{2}$ Mucocele of the sphenoid is usually seen in fourth decade of life, and usually does not have any sex predilection. ${ }^{12}$

Although sphenoid sinus mucocele is pathologically benign, it may involve many vital structures, including the dura, pituitary gland, optic nerve, cavernous sinus, internal carotid artery and cranial nerves (oculomotor, trochlear, trigeminal and abducent nerves) which are vulnerable to injury from the sphenoid lesion. Complications include diplopia, blindness, meningitis, cavernous sinus thrombosis and the compression of the internal carotid artery. $^{3}$

Many patients first consulted ophthalmologists due to visual disturbances, which is common in patients with sphenoid mucocele. ${ }^{2} 3$ Therefore, a good understanding of this disease by ophthalmologists as well as otolaryngologists is essential for early diagnosis and prompt surgical treatment to avoid development of the above-mentioned complications.

Sphenoid sinus mucocele has varied presentations. Headache is the most common symptom (as in our patient). It is usually localised to the supraorbital or retroorbital region. It may be so severe and brings the patient 
to the physician. It has been suggested that headache results from stretching of the dura over the planum sphenoidale. $^{12}$

Visual disturbance is the second-most common symptom, and is mostly because of optic nerve involvement. It can lead to decreased visual acuity and even blindness, which is usually irreversible. ${ }^{2}{ }^{3}$ Visual disturbance can also occur because of the III, IV and VI nerves involvement. The presentation is usually dropping of the upper eyelid, diplopia and restricted ocular movements (external ophthalmoplegia). ${ }^{2-4}$ Sphenoid sinus mucoceles usually do not cause bitemporal hemianopia seen with other sphenoidal and sellar lesions such as pituitary macroadenoma. ${ }^{3} 4$

Nugent et al stated that pain was a common symptom in patients with a sphenoid mucocele. They reported pain in $71 \%$ of their patients. Kennedy et $a l^{5}$ suggested that symptoms of sphenoid mucocele were headache which is occipital or deep seated accompanied with various ophthalmological complications. In some cases, sphenoid sinus mucoceles can present with pain in the distribution of fifth nerve. ${ }^{5}$

Investigations for diagnosing sphenoid sinus mucocele include CT scan of the nose and paranasal sinuses that would show a hypodense cystic lesion in the sphenoid sinus with or without extension to the adjacent sellar, suprasellar, parasellar and retrosellar regions. It has to be differentiated with other cystic lesions seen in this location, such as craniopharyngioma, Rathke cleft cyst, cystic pituitary adenoma, epidermoid cyst, cystic optic nerve glioma and arachnoid cyst. MRI scan of the nose and paranasal sinuses is required to confirm the diagnosis of mucocele. It appears as a cystic homogenous lesion in relation to the paranasal sinuses. MRI is important to detect the extension of the mucocele as well. ${ }^{2} 5$

Treatment of sphenoid mucocele is surgical. ${ }^{5-7}$ The purpose of surgical treatment of the sphenoid sinus mucocele is to create a large ostium that will allow drainage into the sphenoethmoidal recess. Traditionally, the management of sphenoid mucoceles was complete removal via transfacial or transcranial approach. However, endoscopic transnasal sphenoidotomy has largely replaced the conventional open method with excellent results. Marsupilisation of the mucocele via transnasal transsphenoid approach is another option with good results. Recently recommended management of a mucocele of the sphenoid sinus is endoscopic transnasal sphenoidotomy and drainage of the mucocele along with sufficient removal of the anterior and inferior walls of the sinus (as in our case) to allow adequate drainage and to avoid recurrences. ${ }^{5-7}$

On reviewing the literature, it was seen that the visual loss occurring in cases of sphenoid mucoceles is usually irreversible; hence, early surgery is strongly recommended in cases where the vision is at stake and to prevent permanent neurological deficits. ${ }^{2} 3$

\section{Learning points}

- Sphenoid sinus mucocele comprises $1-2 \%$ of all paranasal sinuses mucoceles. Although it is pathologically benign, it may involve many vital structures like the dura, pituitary gland, optic nerve, cavernous sinus and internal carotid artery causing many serious complications.

- Sphenoid sinus mucocele has varied presentations. Headache is the most common symptom. Visual disturbance is the second-most common symptom due to optic or III, IV and VI nerves involvement presenting as decreased visual acuity, diplopia, blephroptosis and external ophthalmoplegia.

- Diagnosis of sphenoid sinus mucocele is by CT scan of the nose and paranasal sinuses that would show a hypodense cystic lesion in the sphenoid sinus with or without extension to the adjacent sellar, suprasellar, parasellar and retrosellar regions. MRI scan is important to detect the extension of the mucocele.

- Treatment of sphenoid mucocele is surgical in the form of endoscopic transnasal sphenoidotomy with sufficient removal of the anterior and inferior walls of the sinus to allow adequate drainage and to avoid recurrences. Marsupilisation of the mucocele via transnasal transsphenoid approach is another option with good results.

- Sphenoid sinus mucocele should be kept in mind in cases of persistent deep-seated headache, visual disturbances and external ophthalmoplegia. We recommend early surgery in these cases in order to prevent permanent blindness or neurological deficits.

Competing interests None.

Patient consent Obtained.

\section{REFERENCES}

1. Friedman A, Batra PS, Fakhri S, et al. Isolated sphenoid sinus disease: etiology and management. Otolaryngol Head Neck Surg 2005;133:544-50.

2. Moriyama H, Hesaka $H$, Tachibana T, et al. Mucoceles of ethmoid and sphenoid sinus with visual disturbance. Arch Otolaryngol Head Neck Surg 1992;118:142-6

3. Lee LA, Huang CC, Lee TJ Prolonged visual disturbance secondary to isolated sphenoid sinus disease. Laryngoscope 2004;114:986-99.

4. Kataria R, Gupta S, Chopra S, et al. Mucocele of the sphenoid sinus: a rare cause of reversible 3(rd) nerve palsy. Ann Indian Acad Neurol 2012;15:158-60.

5. Kennedy DW, Josephson JS, Zinreich SJ, et al. Endoscopic sinus surgery for mucoceles: a viable alternative. Laryngoscope 1989;99:885-95.

6. Har-El G Endoscopic management of 108 sinus mucoceles. Laryngoscope 2001;111:2131-4.

7. Lund VJ Endoscopic management of paranasal sinus mucoceles. $J$ Laryngol Otol 1998;112:36-40. 


\section{BMJ Case Reports}

This pdf has been created automatically from the final edited text and images.

Copyright 2012 BMJ Publishing Group. All rights reserved. For permission to reuse any of this content visit http://group.bmj.com/group/rights-licensing/permissions.

BMJ Case Report Fellows may re-use this article for personal use and teaching without any further permission.

Please cite this article as follows (you will need to access the article online to obtain the date of publication).

Bahgat M, Bahgat Y, Bahgat A. Sphenoid sinus mucocele. BMJ Case Reports 2012;10.1136/bcr-2012-007130, Published XXX

Become a Fellow of BMJ Case Reports today and you can:

- Submit as many cases as you like

- Enjoy fast sympathetic peer review and rapid publication of accepted articles

- Access all the published articles

- Re-use any of the published material for personal use and teaching without further permission

For information on Institutional Fellowships contact consortiasales@bmjgroup.com

Visit casereports.bmj.com for more articles like this and to become a Fellow 